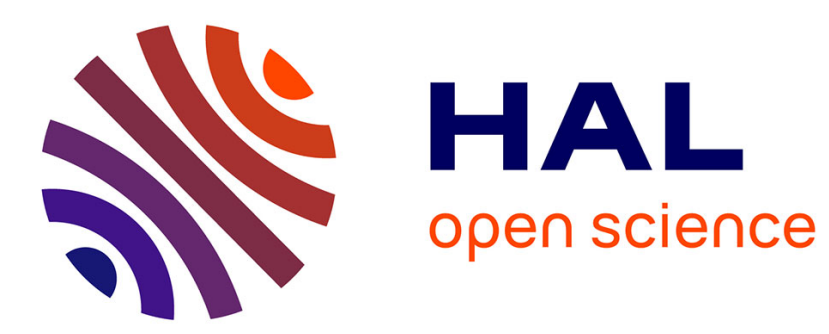

\title{
Between Fact and Fiction: Semantic fields and Image Content in Crime Infotainment programs
}

Gaëlle Ferré

\section{To cite this version:}

Gaëlle Ferré. Between Fact and Fiction: Semantic fields and Image Content in Crime Infotainment programs. Multimodal Communication, 2016, 5 (2), pp.127-141. 10.1515/mc-2016-0018 . hal01422539

\section{HAL Id: hal-01422539 \\ https://hal.science/hal-01422539}

Submitted on 26 Dec 2016

HAL is a multi-disciplinary open access archive for the deposit and dissemination of scientific research documents, whether they are published or not. The documents may come from teaching and research institutions in France or abroad, or from public or private research centers.
L'archive ouverte pluridisciplinaire HAL, est destinée au dépôt et à la diffusion de documents scientifiques de niveau recherche, publiés ou non, émanant des établissements d'enseignement et de recherche français ou étrangers, des laboratoires publics ou privés. 


\title{
Between Fact and Fiction: Semantic fields and Image Content in Crime Infotainment programs
}

\author{
Gaëlle Ferré \\ English Department, LLING (UMR 6310 CNRS) \& Université de Nantes Pôle Lettres Langues \\ Sciences Humaines et Sociales, Nantes cedex 3, France \\ Gaelle.Ferre@univ-nantes.fr
}

\begin{abstract}
Crime infotainment is a hybrid type of television program in which each episode is based on a real criminal case and presented to the audience under the form of a reconstructed narrative. Research has shown that although violent crime is ubiquitous in other types of media, leading to an overrepresentation of violent content, crime infotainment is the most fear-inducing type of media as compared with newspaper coverage and television crime drama. This leads people to believe their lives are at risk and they consequently support cultural conservative politics of anti-crime measures which are excessive considering the risk. It is therefore important to understand how crime infotainment content is built to induce fear. Adopting the framework of Ideological Discourse Analysis developed by van Dijk (1995a, 1995b, 2006), the study presented here proposes an analysis of three French infotainment stories, comparing the semantic fields in their speech with the semantic fields developed in related newspaper articles. The study also proposes an analysis of image content in infotainment which leads us to the conclusion that the blurring of the lines between what is presented as (discursive) fact or (imagistic) fiction may well have a consequent impact on the audience.
\end{abstract}

\section{Keywords}

Crime infotainment, semantic content, multimodality, Ideological Discourse Analysis

\section{Introduction}

Although not a new phenomenon since early media, especially the radio, were already concerned with crime and justice (Surette, 2011: 11), violent crime has become so ubiquitous in the media that it has led many scholars to ponder the ideological impact this over-representation necessarily has on the audience. Crime-and-justice stories have indeed been estimated to account for about one-fourth of all entertainment shows on television (ibid.: 16) and at least one crime drama can be viewed on television in prime time almost any night of the week (Lam, 2014: 12). Violent crime is overrepresented not only in television fiction but also in newspaper articles (Reiner, 2002), although the "percentage of television devoted to crime news is even higher than newspapers" (Callanan, 2005: $60)$, and other television programs like what has been called infotainment. Infotainment has been defined as a hybrid type of program that mixes entertainment and news (Callanan, 2005: 74) and "has emerged to create a niche between news and entertainment" (Surette, 2011: 15) that "combines aspects of news, entertainment, and advertising under a single umbrella" (ibid.: 19). In infotainment programs, also sometimes called 'docudramas', real crime stories are told using a combination of documentary storytelling and fictional reenactments of crime (Lam, 2014: 143). 
Not only is crime generally over-represented in the media in total contradiction with actual crime statistics (Cavender and Bond-Maupin, 1993: 306), but "the crimes which are statistically most uncommon are most frequently featured" (Jewkes, 2004: 157) with a strong focus on violent homicides and rapes. Katz notes that "murders and rapes, among the least frequent crimes in FBI statistics, are among the most frequent crime subjects" (1987: 60). Crimes are also presented as random, meaningless and unpredictable acts of extreme violence (Callanan, 2005, Jewkes, 2004) and the stories depicted in the media present a distorted picture of criminals and victims (Cavender and Bond-Maupin, 1993, Smolej, 2011). Victims are highly idealized and presented as innocent beauties, whereas criminals are strongly stigmatized as bestial deviants. This misrepresentation has been shown to have an impact on the audience and most surveys show that it strongly increases fear of crime (Callanan, 2005: 3). Infotainment programs also present a distorted picture of crime (ibid.: 74) and it has been shown that this type of program is more fear-inducing than the print media or television crime fiction (ibid.). Callanan notes that watching infotainment encourages punitive attitudes in the audience and elevates support of a crime control stance, the reason being that infotainment presents an extremely blurred line between fiction and fact, or entertainment and news (Kohm, 2009: 193) and can be described as "dramatized programs disguised as in-depth reporting" (Kort-Butler and Sittner Hartshorn, 2011: 39). It is therefore essential to research this type of programming, so as to better understand how the blurring between fact and fiction is achieved as one may believe this to be their most fear-inducing feature. Understanding how crime is presented in the media is important to understanding "how crime issues become salient to viewers" (Callanan, 2005: 58).

In this study, which adopts the framework of Ideological Discourse Analysis developed by T. van Dijk (1995a, 1995b, 2006), a corpus of 3 French infotainment episodes and its treatment will be described in section 2. Section 3 presents the results of the analysis beginning with some context on crime and offenses in France (section 3.1) before delving into a detailed analysis of crime infotainment and related newspaper articles into thematic fields (section 3.2). Section 3.3 will discuss the image content of crime infotainment before a conclusion is reached in section 4 .

\section{Theoretical Background}

Crime infotainment programs, also called 'docudramas' by some academics (Lam, 2014), constitute a hybrid television genre that mixes up features of news and fiction. Their "framing is deliberately dramatic so that the policy-relevant aspects of news are often overshadowed by entertainment features" (Graber, 1994: 483). Nabi et al. notice that they "depict crime in ways similar to those used in fictionalized crime shows" (2003: 311). They feature extremely simple stories of 'easily dramatized' violent crimes (Cavender and Bond-Maupin, 1993, Innes, 2003) which most of the time "differ only in details about time, place and the identities of victim and defendant" (Katz, 1987). These programs generally employ dramatizations of actual crimes intertwined with narrative and interviews of police, magistrates and journalists (Surette, 2011: 22). Dramatization features reenactments by actors of the scenes described, interviews of victim and defendant's relatives, pictures of victims showing them in 'happier times', interviews of journalists who have covered the case, CCTV footage, computer 3D reconstructions or any other image that will present the crime "in a graphic and sensationalized manner" (Jewkes, 2004: 105). All these 'scenes' are intertwined into an assemblage that constructs a narrative. The audience of infotainment mainly seeks entertainment in this kind of program (Nabi et 
al., 2003), that makes a strong use of "symbolism and emotionally laden frames in order to capture audience interest" (Callanan, 2005: 59). In infotainment programs, "emotional hooks are constructed around personal involvement narratives" (Cavender and Deutsch, 2007: 72) that are conveyed with the use of visuals, verbal narratives and appropriate sounds and music, "fear-evoking cues magnified by sophisticated cinematographic techniques" (Cavender and Bond-Maupin, 1993: 311). Thus, the "macro-, meso- and micro-levels of textual organization, construct the killing from a particular perspective as a news 'story'" (Haig, 2008: 33). According to Greer, crime stories are generally selected and edited as media events on the basis of their visual potential (2007: 29) as this "constitutes perhaps the central medium through which the meanings and emotions of crime are captured" (Greer et al., 2007: 5).

What is important however, is that the audience is absolutely not aware they are shown "a heavily reconstructed piece of reality" (Surette, 2011: 93). Crime is presented as totally detached from the sociological context in which it occurs (Cavender and Bond-Maupin, 1993) and the audience is given the feeling that only punitive responses cam hamper this social evil. The ubiquitous presence of random, violent crime in the media and infotainment in particular, affords a ritual experience of collective moral outrage to the audience that helps them build a community of thought in which they can construct the US/THEM dichotomy that is essential for them to build a sense of belonging (van Dijk, 1995b). Infotainment can then be seen "not as a source of information about crime but as a morally charged message about other issues of interest" (Katz, 1987: 54), in which crime features as a social construct and which reinforces preexisting ideologies (Tabbert, 2015). As stated by Haig, the news media's role is not inform and educate the public but "to influence audiences in line with particular perspectives conducive to maintaining rather than changing the social order" (Haig, 2008: 33). While capturing a large audience with elements of entertainment similar to those found in crime dramas, infotainment relies on a large part on the so-called realism afforded by the news media. Whereas "viewers approach crime dramas with more skepticism than crime news or infotainment because they know it is fictional" (Callanan, 2005: 172), they are generally more affected by television news and infotainment programs.

Kort-Butler \& Sittner Hartshorn indeed found a strong correlation between the frequency at which people watch crime programming and fear of crime (2011: 48), whereas several authors observed no direct relationship between the viewing of crime drama and an increase in fear of crime (Callanan, 2005, Kort-Butler and Sittner Hartshorn, 2011). Callanan also found a stronger correlation between fear of crime and watching crime-related programs than reading about crime in the print media (Callanan, 2005: 149). The fight against individuals who disrupt social order by committing violent killings, a dominant topic of infotainment programs, become a staple of public policies as "politicians respond to the outcry" of the population (Callanan, ibid.: 8) and "public responses to crime have been placed at the top of a highly politicized crime agenda" (Peelo, 2006: 159), leading to more and more conservative anti-crime measures and a more Orwellian-inspired society. Whereas liberals emphasize social improvements to prevent crime and rehabilitation as an adequate response to crime, cultural conservatives' favor crime control with increased police force, maintenance of social order with more effective surveillance means and harsh punishment for crime (Lenz, 2005).

It is therefore of the utmost importance to understand in a more systematic way what is specific to infotainment programs that makes them different from or similar to newspaper articles on crime or 
crime dramas and may explain why they appear to be more fear-inductive than other crime-related media. With this perspective in mind, the study presented in this paper, which is part of a larger project on crime infotainment, examines the semantic content of the narratives delivered in infotainment programs as well as the visual information simultaneously conveyed to the audience.

\section{Corpus and methodology}

\subsection{Videos}

The corpus used for this study consists of three stories edited by three different French infotainment programs and which are directly inspired from American programs. All three stories are available online. The first story, Affaire Chabé : le pompier, l'amant et la secrétaire ("The Chabé case: the fireman, the lover and the secretary"), was part of the program Chroniques criminelles (2014), and tells the story of a young wife who had been strangled and was found lying dead on the kitchen floor by her husband when he came back from work in 2008, in a small town in Picardie. Her death is presented as highly unexpected until the police discover that she had an affair and has thus probably not been the loving wife that everyone described. The interest in this story is however that her husband, who was found guilty in a first trial and then cleared in Appeal, features as the main witness and the program shows that the police have been particularly incompetent with the inquiry, as they disregarded and even ruined essential pieces of evidence. The whole story is therefore developed using the "bad cop frame" described by Surette (2011: 84-85). The story lasts 39:35 minutes and counts 6.229 words.

La maison de l'horreur ("The horror house") in Suspect $n^{\circ} 1$ (2013) describes the murder of a student in 1997 and the discovery that the year before, the offender had also murdered his sister-in-law, then aged 17. He had buried both bodies in his garden in a village of Normandy. He was found guilty and sentenced to life imprisonment. The story lasts 58:35 minutes and counts 8.226 words.

L'Affaire Aurélie Fouché: meurtre à la ferme ("Aurélie Fouché: murder at the farm") in Enquêtes criminelles (2014) depicts the murder of a young mother by her ex-partner in 2011 in a farm of Cagnes-sur-Mer, a small town in Alpes-Maritimes. After he cut her throat, he threw her body into the manure pit and covered it with quick lime. He was also found guilty and sentenced to life imprisonment. The story lasts 54:50 minutes and counts 8.091 words.

The three stories were entirely transcribed in syntactic clauses using the Praat software (Boersma and Weenink, 2009) and this transcription was then aligned with the videos using ELAN (Sloetjes and Wittenburg, 2008), in which discourse moves ii were noted as well as voices (who speaks when) and image content on a frame-by-frame basis.

\subsection{Newspaper articles}

Additionally, newspaper articles on the same three cases were collected for a comparison (total word number: 18.941), both from local papers like Le courier picard, Le petit niçois or broadsheets like Libération or Paris Match. The interest in choosing exactly the same cases was that newspaper content is very varied and it is difficult to compare semantic content as well as the internal organization or the development of stories over time if we select just any type of press article, whose 
content ranges from crime stories to sport events and politics. Whereas newspaper articles were used for a semantic comparison with infotainment, image content was not compared with what is found in videos as many more articles would have been needed to enable a comparison.

\subsection{Semantic treatment of both videos and newspaper articles}

The transcription files of the videos and newspaper articles were edited into raw text files that would enable their treatment by the tool AntConc (Anthony, 2014) for an analysis of their semantic content. Each text was edited so that compounds (e.g. garde à vue "police custody", Cour d'Appel "Court of Appeal"), as well as adverbial or set phrases (à peu près "about") but also semantic units (like dates or figures for instance) were counted as single words in the tool and word frequencies for each case were then exported to an Excel calculation sheet, in which words were classified into thematic fields using the methodology adopted by Chabot et al. (2008) and Bednarek (2016). Only nouns, verbs, adverbs and adjectives were considered and some words could belong to several thematic fields. Whereas some thematic fields were specific to some morphological categories, others were found across categories and these present a particular interest. The idea was to describe semantic content and see whether there is a difference in this respect between stories in newspaper articles and stories in infotainment.

\section{Results and discussion}

\subsection{Some context: mortality and crime rates in France}

Before going into the details of the semantic and discourse analysis of the three videos and the newspaper articles, it sounds important to provide some context on mortality and crime in France at the date when the programs where aired on television. The government administration publishes reports every year, but detailed figures for 2014 and 2015 are not yet known. However, it is very unlikely that the rate of homicides has drastically risen in one year, so we will consider 2013 as an appropriate date to evaluate whether crime content on television is over-represented in France in the same way as it is in the US.

With 777 reported cases in 2013 (release date of one of our videos), homicides represent only $0.14 \%$ of the total number of deaths for that year (558.408 deaths in 2013 at a national level as published by the INSEE ${ }^{\mathrm{iii}}$ ).

Detailed figures on crime and delinquency for 2013 were released by the ONDRP ${ }^{\text {iv }}$, which publishes all the crimes and offenses reported by police departments on a national scale, and which are summarized in Table 1 below:

\begin{tabular}{l|rr} 
& NB & $\%$ \\
\hline \hline Homicides & $\mathbf{7 7 7}$ & $\mathbf{0 . 0 2}$ \\
Offenses against property & 2.222 .790 & 63.28 \\
Offenses against people & 493.521 & 14.05 \\
Frauds & 331.551 & 9.44 \\
Breaches of the law & 327.936 & 9.34
\end{tabular}




\begin{tabular}{l|rr} 
Other & 136.188 & 3.88 \\
TOTAL & $\mathbf{3 . 5 1 2 . 7 6 3}$ & 100
\end{tabular}

Table 1. Number and percentage of crimes and offenses reported by police departments in 2013 in France

These results confirm what was found in previous research for different countries (especially the US and the UK) that in 2013, when the programs were first aired, the French were more likely to die of old age, illness or a car accident than by homicide in the first place, and secondly, that with only $0.02 \%$ of all crimes and offenses reported by police departments in 2013, homicides represent an almost insignificant proportion of crimes and offenses (total number: 3.512.763), whereas cases of offenses against property and people, fraud and breaches of the law are much more numerous. Besides, the figures given by the ONDRP concerned crimes and offenses at a national level, but we have seen that the three cases presented in the videos occurred in small towns or even villages making the probability of being murdered appear to be even higher than in larger cities, as observed by Chermak and Chapman (2007: 354).

\subsection{Semantic analysis of videos and newspaper articles}

In videos that feature violent crime in a most dramatic fashion, one expects to find much of its semantic content to be in relation with crime and violence, as well as vocabulary expressing emotions. Besides, as has been shown in the theoretical background section of this study, this type of television program is very much victim-centered and the victim is typically presented as part of a family and therefore of a community with which the audience can empathize. This should be reflected as well in the vocabulary used. The sections below present a comparison of the 5 most frequent thematic fields represented in the vocabulary of infotainment and newspaper articles for nouns, verbs, adverbs and adjectives respectively, and then the 5 most frequent thematic fields across morphological categories.

\subsubsection{Thematic fields for nouns in infotainment and newspaper articles}

Nouns in infotainment and newspaper articles are very similar in terms of the 5 most frequent thematic fields they belong to as shown in Table 2 below:

\begin{tabular}{l|cccc}
\multicolumn{2}{c}{} & \multicolumn{2}{c}{ Infotainment } & \multicolumn{2}{c}{ Print media } \\
\hline \multirow{3}{*}{ Names } & NB & \% & NB & $\%$ \\
\cline { 2 - 5 } Relationships & 908 & $\mathbf{1 8 . 9}$ & 738 & 13.1 \\
Time & 774 & $\mathbf{1 6 . 1}$ & 524 & 9.3 \\
Inquest/trial & 571 & 11.9 & 807 & $\mathbf{1 4 . 3}$ \\
Space & 504 & 10.5 & 1173 & $\mathbf{2 0 . 8}$ \\
\hline Total number of nouns & 412 & 8.6 & 467 & 8.3 \\
\hline
\end{tabular}

Table 2. Number and percentage of nouns that constitute the 5 most frequent thematic fields in infotainment and print media 
Out of 4,804 nouns in infotainment, emphasis clearly lies on people's names (especially victim and offender) that represent $18.9 \%$ of nouns and relationships (16.1\% of nouns; wife, daughter, husband, neighbor...), showing a victim-centered angle in which victims "are constructed not as individuals in and of themselves but as spouses, children, siblings and parents [...] to not be in a family would be to not be a proper victim" " (Jermyn, 2003: 184-185). The most frequent thematic field out of the 5,630 nouns in press articles is related to the inquest and trial ( $20.8 \%$ with nouns like autopsy, interrogation, trial, court...), but there is an emphasis as well on terms that denote temporality (14.3\% of nouns naming months, days...). It is interesting however to note that temporality and legal procedure count among the $5^{\text {th }}$ most frequent thematic fields in infotainment as well, with terms related to space (place names and locations) coming in the same position as in newspaper articles. This denotes a certain concern for precision and objectivity and achieves the effect of "ultra-realism" described by Reiner (2002: 379). In two of the videos, some of the nouns employed are even more formal in infotainment programs than in the print media, when the contrary would have been expected. For instance, Antconc reveals that in the Chabé case, the French word "épouse" (spouse) is significantly more frequent in the video than in the written press where the more generic word "femme" (wife) is preferred. In the same video, we find 2 occurrences of the formal word "astreinte" (on-call duty) when the print media uses the more familiar word "garde" (duty). Similarly in the Griffin case, the formal word "domicile" (place of residence) is preferred in the video over the more familiar "maison" (house) that is found in the written press. Some other formal words are simply more frequent in the videos than in the print media: the word "véhicule" (vehicle) is met only twice in the written press for the three cases, whereas the more familiar word "voiture" (car) is met 6 times. In the three videos, there are 14 occurrences of the word "véhicule" contra 37 occurrences of the word "voiture". This means that the proportion of the more formal word is slightly higher in infotainment than in the print media when synonyms can be used.

Coming back to Table 2, what is not shown but is nevertheless interesting is that nouns denoting emotions come only in $8^{\text {th }}$ position out of 13 categories and represent only $5 \%$ of all nouns for infotainment, whereas they come in $10^{\text {th }}$ position out of 13 for press articles and represent only $1.5 \%$ of nouns for the print media. Nouns related to murder or violence only arrive in $10^{\text {th }}$ position and represent $4.9 \%$ of nouns for infotainment. They come in $6^{\text {th }}$ position and represent $6 \%$ of nouns for newspaper articles. This shows that whereas vocabulary linked with emotion is of the same order in the two media types, vocabulary linked with violent crime is slightly more present in newspaper articles than in infotainment.

\subsubsection{Thematic fields for verbs in infotainment and newspaper articles}

In the same way as for nouns, we expected a high number of verbs to reflect emotional content (e.g. shout, cry...) or to be related with murder and violence (kill, strangle...). Table 3 below shows that out of 2,422 verbs murder arrives in second position in the thematic fields of newspaper articles with $11 \%$ of verbs in this category whereas it arrives only in $10^{\text {th }}$ position out of 13 categories in infotainment and represents only $4 \%$ of 2,782 verbs. Verbs related with the procedure of the inquest/trial (interview, investigate, appeal, confess...) are the most frequent ones in newspaper articles $(23.6 \%)$ and only come in $12^{\text {th }}$ position with a frequency of $2.8 \%$ in infotainment. Verbs of actions (do, make, act...) reach the same position in both media types, although they are slightly more frequent in infotainment than in newspaper articles. An explanation for this may be that these 
verbs are generally more frequent in spoken language than in written language, and are therefore expected to be slightly more numerous in a medium which relies on speech like infotainment than in the print media. What is interesting in Table 3 though is the high frequency of verbs of saying (say, add, answer...) in infotainment where they constitute the highest frequency verbs $(14.1 \%$ of all verbs) whereas they are twice less numerous in newspaper articles, although most instances of reported speech are generally followed by a quotative. We note also the very high frequency of verbs of knowledge (positive or negative verbs like know, doubt, believe...) in infotainment $(13,7 \%$ of all verbs) that only come in $11^{\text {th }}$ position out of 12 categories for newspaper articles, which shows that infotainment producers are very much concerned with acknowledging the state of knowledge regularly in the program. This is counterbalanced by the relatively high use of modal verbs (especially should and could ${ }^{v}$ ) in newspaper articles, which are mainly focused on the narration of the trials on a day-to-day basis with predictions on the outcome. Although modality does not count as one of the main thematic topics in infotainment, its use is quite high as well in this type of media since it represents $8.4 \%$ of all verbs and comes in $6^{\text {th }}$ position out of 13 categories.

As a last comment on the table, we note that in infotainment, verbs denoting space (lead to, move away from, join...) and time (continue, precede, finish...) count among the $5^{\text {th }}$ most frequent types of verbs and echo the categories found for nouns in that they denote some concern for precision on location in time and space of all the facts and people involved in the story.

\begin{tabular}{l|lrlrr}
\multicolumn{1}{c}{ Infotainment } & \multicolumn{3}{c}{ Print media } \\
\hline \multirow{3}{*}{ Saying } & NB & \% & & NB & \% \\
\cline { 2 - 7 } Knowledge & 393 & $\mathbf{1 4 . 1}$ & Inquest/trial & 571 & $\mathbf{2 3 . 6}$ \\
Action & 381 & $\mathbf{1 3 . 7}$ & Murder & 266 & $\mathbf{1 1 . 0}$ \\
Space & 326 & 11.7 & Action & 187 & 7.7 \\
Time & 304 & 10.9 & Saying & 179 & 7.4 \\
\hline total number & 301 & 10.8 & Modality & 133 & 5.5 \\
of verbs & & & & & \\
\end{tabular}

Table 3. Number and percentage of verbs that constitute the 5 most frequent thematic fields in infotainment and the print media

\subsubsection{Thematic fields for adjectives in infotainment and newspaper articles}

As far as adjectives are concerned, one could expect to find many negative adjectives to emphasize the atrocity of the murder and although these come in $3^{\text {rd }}$ and $4^{\text {th }}$ position in Table 4 , we note that positive adjectives (beautiful, nice, gentle...) are more numerous: they come in $1^{\text {st }}$ position for infotainment ( $27.5 \%$ of 1,421 adjectives) and in second position in press articles (15.3\% of 856 adjectives) and show that emphasis is strongly put on the victim in both media types, and especially on some idealized version of the victim.

If it is quite normal to find a great number of 'neutral' adjectives (yellow, round, industrial...) in both media, what should be noticed is that there is quite a strong emphasis on adjectives that denote quantity (with all the numeral adjectives besides indefinite quantifiers like many, several...) showing 
the constant need to be as factual as possible (33.9\% for infotainment and $21.7 \%$ for the print media). Whereas newspaper articles contain quite a high number of adjectives linked to the crime or the legal procedure (judiciary, criminal, innocent, guilty...) representing $14 \%$ of all adjectives, these only come in $8^{\text {th }}$ position out of 9 thematic categories for infotainment and represent $3.7 \%$ of all adjectives in this type of media. Emotions (happy, jealous, joyous...) however figure among the 5 most frequent categories in infotainment, whereas they only come in $11^{\text {th }}$ position out of 12 categories for newspaper articles and represent only $0.4 \%$ of all adjectives.

\section{Infotainment}

\begin{tabular}{l|cclccc}
\hline & NB & \% & & NB & $\%$ \\
\cline { 2 - 6 } Positive & 391 & $\mathbf{2 7 . 5}$ & Quantity & $\mathbf{1 8 6}$ & $\mathbf{2 1 . 7}$ \\
Quantity & 482 & $\mathbf{3 3 . 9}$ & Positive & $\mathbf{1 3 1}$ & $\mathbf{1 5 . 3}$ \\
Negative & 148 & 10.4 & Crime/trial & $\mathbf{1 2 0}$ & $\mathbf{1 4 . 0}$ \\
Neutral & 135 & 9.5 & Negative & 60 & 7.0 \\
Emotions & 116 & 8.2 & Neutral & $\mathbf{4 8}$ & 5.6 \\
\hline Total number of & $\mathbf{1 4 2 1}$ & & & $\mathbf{8 5 6}$ &
\end{tabular}

\section{adjectives}

Table 4. Number and percentage of adjectives that constitute the 5 most frequent thematic fields in infotainment and the print media

\subsubsection{Thematic fields for adverbs in infotainment and newspaper articles}

As far as adverbs are concerned (Table 5), both types of media show a high proportion of adverbs expressing quantity (totally, almost, only...) and time (regularly, quickly, often, never...) but whereas temporal adverbs reach a high percentage with $37.4 \%$ in newspaper articles contra $25.9 \%$ in infotainment, it is quantity that comes in first position in infotainment representing $28.4 \%$ of the 844 adverbs (vs. $25.0 \%$ of the 880 adverbs for the print media). Unsurprisingly, manner adverbs (calmly, imperturbably, brusquely...) are frequent in both media types (10.2 \% of adverbs in infotainment and $20.5 \%$ in the print media) as well as adverbs that show discourse relations between sentences (yet, nevertheless...). The difference between the two types of media is that whereas space adverbs (here, there...) are quite present in newspaper articles, they represent only $0.4 \%$ of adverbs in infotainment. In turn, the adverbs in infotainment frequently express the degree of certainty of the speaker (probably, maybe, obviously...) with a frequency of $20.5 \%$ which echoes what we have seen for verbs, i.e. a constant desire to be precise on the state of knowledge of the speaker. Such epistemic adverbs represent only $1.6 \%$ of all adverbs in newspaper articles and come in $6^{\text {th }}$ position out of 7 categories.

\begin{tabular}{l|cclcc}
\multicolumn{3}{|c}{ Infotainment } & \multicolumn{3}{c}{ Print media } \\
\hline \multirow{2}{*}{ Quantity } & NB & \% & & NB & \% \\
\cline { 2 - 6 } Time & 240 & $\mathbf{2 8 . 4}$ & Time & 329 & $\mathbf{3 7 . 4}$ \\
(Un)certainty & 219 & $\mathbf{2 5 . 9}$ & Quantity & 220 & $\mathbf{2 5 . 0}$ \\
Discourse & 173 & $\mathbf{2 0 . 5}$ & Manner & 180 & $\mathbf{2 0 . 5}$ \\
Manner & 99 & 11.7 & Space & 47 & 5.3 \\
\hline
\end{tabular}


Total number of

adverbs

Table 5. Number and percentage of adverbs that constitute the 5 most frequent thematic fields in infotainment and the print media

\subsubsection{Thematic fields across morphological categories in infotainment and newspaper articles}

Collapsing the five morphological categories yields the results shown in Table 6 below:

\begin{tabular}{|c|c|c|c|c|c|}
\hline \multicolumn{4}{|c|}{ Infotainment } & \multicolumn{2}{|c|}{ Written press } \\
\hline & NB & $\%$ & & NB & $\%$ \\
\hline Time & 1091 & 11.1 & Inquest/trial & 1744 & 17.8 \\
\hline Names & 908 & 9.2 & Time & 1187 & 12.1 \\
\hline Relationships & 830 & 8.4 & Names & 738 & 7.5 \\
\hline Quantity & 737 & 7.5 & Relationships & 660 & 6.7 \\
\hline Space & 731 & 7.4 & Crime & 605 & 6.2 \\
\hline
\end{tabular}

Table 6. Number and percentage of words across morphological categories that constitute the 5 most frequent thematic fields in infotainment and the print media

What is shown in Table 6 is a different focus and arrangement of the thematic fields: people's names and relationships occupy a large part of the lexical content in both types of media as well as temporal landmarks (11.1\% in infotainment and $12.1 \%$ in the print media), but whereas for infotainment, quantity and spatial landmarks are quite dominant, reflecting a concern for precision, the focus is rather more on the murder and the legal procedure that ensues in newspaper articles $(6.2 \%$ for crime and $17.8 \%$ for lexical items related to the inquest/trial). Emotions are not amongst the $5^{\text {th }}$ most frequent thematic fields in any of the two media types. What we can conclude from this, is that infotainment tells us the story of people, at a certain time and in a certain place with great emphasis on precise figures with phrases like the call lasted 11 minutes and 54 seconds, and these people are part of a community. Newspaper articles also mention people and their being part of a social community, but insist on the crime and the following procedure.

Semantically speaking, newspaper articles are more related to violence, crime and punishment than infotainment which should therefore be less anxiety-provoking than the print media. Since it has been shown in the theoretical background of this paper that this is not the case, the reason must be sought elsewhere, which is why we now present an analysis of their image content.

\subsection{Image content in infotainment}

In view of what has been described in the introduction and theoretical background sections of this paper, one might expect image content in the videos to be oriented towards victims and their relatives so as to arouse emotional involvement in the viewers. We also expect images of police officers to represent an important contribution to infotainment programs, since showing that the 
police have been efficient in solving a case may justify support for more conservative measures as they "are seen to be highly effective instruments of social order" (Cotter et al., 2008: 285). Yet, in view of the semantic analysis of this type of program presented in section 3.2, we may also expect a dominance of image content oriented towards a factual recounting of the story. The picture provided by Table 7 below provides a clear account of image content in our three videos:

\begin{tabular}{l|cc} 
Image content & Duration(in sec) & $\%$ \\
\hline Reenactment & 3735.6 & 40.7 \\
Victim (includes pictures and films of victim alone or with & 1015.9 & 11.1 \\
family, victim's relatives, house of victim, CCTV footage) & & \\
Magistrates (includes judges, attorneys, lawyers, prosecutors) & 772.8 & 8.4 \\
Defendant (includes pictures and films of defendant, & 725.2 & 7.9 \\
defendant's relatives) & & \\
Police \& experts & 538.5 & 5.9 \\
Journalists who have worked on the case & 492.8 & 5.4 \\
Quotations (includes archive images, broadcast news bulletins, & 445.6 & 4.9 \\
images of newspaper articles) & & \\
Transition images & 326.4 & 3.6 \\
Other (includes written titles, credits \& unidentifiable image & 287.6 & 3.1 \\
content) & 257.8 & 2.8 \\
Split screen & 249.1 & 2.7 \\
Landscape & 241.3 & 2.6 \\
Official building & 90.5 & 1.0 \\
Technology (includes animated maps, close-ups on text & & \\
messages, computer animated images) & 9179.1 & 100 \\
TOTAL &
\end{tabular}

Table 7. Image content in infotainment programs sorted by duration of image type in seconds and percentage of content

Table 7 shows that the major part of infotainment programs is made up of reenactment scenes ( $40.7 \%$ of image content) in which actors play the roles of victim and defendant. This means that in terms of image content, infotainment programs are closer to crime dramas than to news programs. Even if we add up images showing magistrates, journalists, police officers, experts and direct quotations, which together present a picture more anchored into realism, we do not reach the duration of reenactment scenes. Content related to the victim comes in second position in terms of image duration and this type of program constructs a clear triangular relationship between victim, magistrates and defendant, whereas police officers and journalists who have worked on the case are less represented. Other elements that could give a more realistic aspect to the program, like archive images (of arrest or trial), setting of the action (landscapes) and official buildings only amount to a total of $10 \%$ when counted together. The split-screen technique, in which most of the time a journalist or a magistrate is shown on one side of the screen whereas the other side shows either a picture of the victim or a reenactment scene (Figures $1 \& 2$ ), makes up less than $3 \%$ of the program, although its use is very reminiscent of journalistic film edition. A last comment on Table 7 is that use 
of technological devices like computer animated images, that could give the program a more scientific aspect, is almost nonexistent.

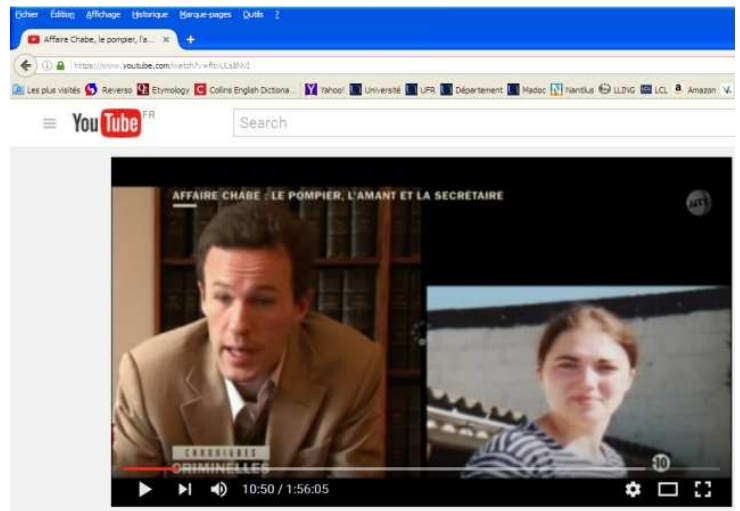

Figure 1. Split-screen showing a magistrate (left) and a picture of victim (right)

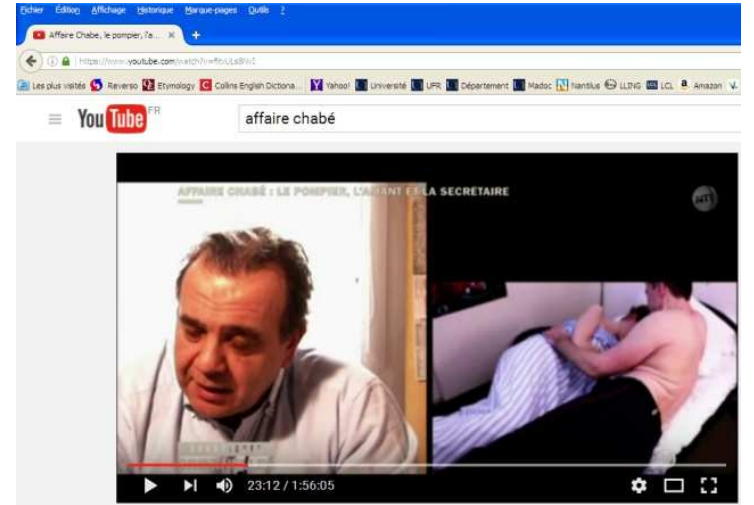

Figure 2. Split-screen showing a journalist (left) and a reenactment scene (right)

\subsubsection{Information content}

If one might have expected crime infotainment to be saturated with violent content and even disturbing images which would serve this highly dramatic type of media and which would certainly arouse emotion in the audience and increase fear of crime, this is absolutely not the case. Even in reenactment scenes, crime is evoked rather than actually shown: for instance, in two of the cases examined in this study, quite a lot of blood must have been shed by victims since one of them had her throat slit and the other died after her assailant banged her head several times against a beam in his sitting-room. Although the murder scene is reenacted several times in this latter case, no blood is visible in the images. Most of the reenactment sequences are even oriented towards more mundane life scenes in which the victim is seen with her family or driving to work. In the former case, the murder itself is not reenacted and the content of reenactment sequences is almost exclusively centered on the search for the victim when she went missing. In the remaining video, the victim was strangled with her scarf and reenactments scenes do not show the murder action either, but rather feature the victim lying on the floor, a shot generally ending with an extreme close-up on the scarf, and which is repeated several times in the episode. Image content is then pretty much in line with the semantics of narration in infotainment programs, since the focus is absolutely not on the crime itself, but rather on the interaction between people. The constant re-use of film footage that convey little information content on the crime to the audience, or which is purposefully blurred or difficult to see as shown in Figure 3, can be seen as a "strategic structuring device" (Haig, 2008: 37) thanks to which crime stories become "routinized through repetitive and formulaic depiction" (Kohm, 2009: 193).

If dramatic effects are not created in infotainment programs under the form of disturbing image content, some other elements may however contribute to the dramatization in the program: film transitions. Most transitions between scenes or shots consist in the ordinary fade-outs to black (total duration: $172.7 \mathrm{sec}, 52.9 \%$ of transitions) while few transitions use the dissolving technique (duration: $31.6 \mathrm{sec}, 9.7 \%$ of transitions). However, an important proportion of fade-outs also use brief fades to white or red (total duration: $122.1 \mathrm{sec}, 37.4 \%$ of transitions). These film transitions are 
particularly eye-catching, fade-outs to white evoking ghost stories in films or paranormal documentaries and fade-outs to red, horror movies.
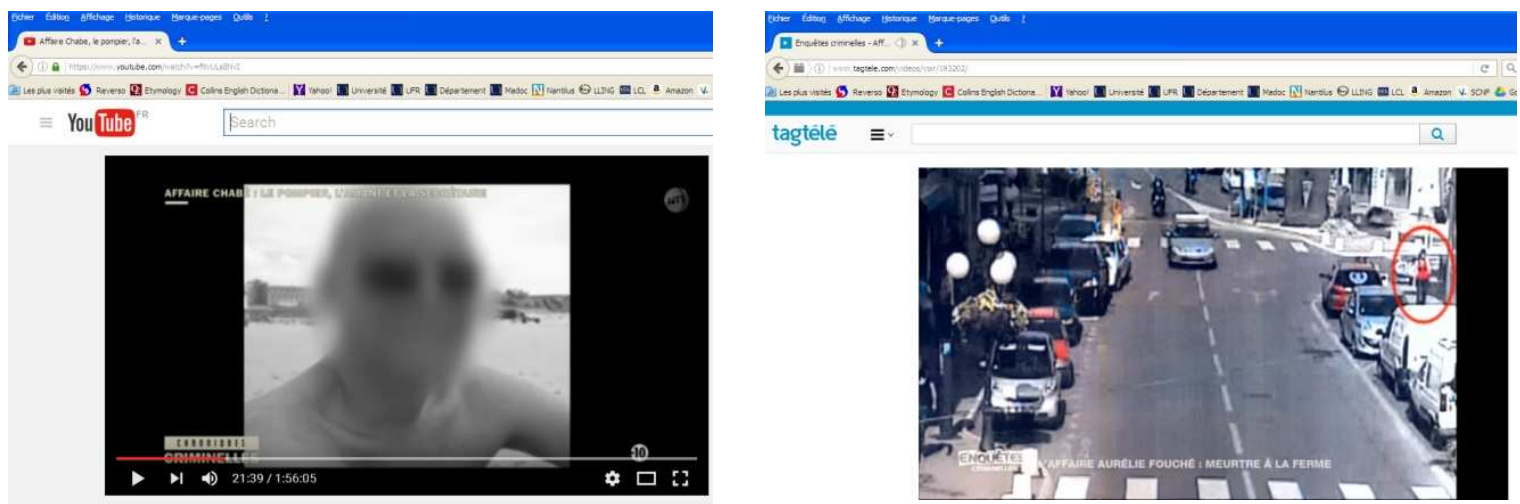

Figure 3. Poor information content: best shot of lover in the Chabé case (left) and CCTV footage of victim in the Fouché case (right)

\subsubsection{Photos of the victim}

More repetition is observed when considering the use of pictures of the victim that tie her "to familiar kinds of roles, spaces and values that the audience will, presumably, largely understand and share" (Jermyn, 2003: 188). Our three videos show different patterns in this respect, although repetition is the most frequent one. In one of the videos (Suspect $n^{\circ} 1$ ), little use is made of pictures of the victim with only 3 pictures shown in total and which are not re-used in the videos. In this particular program, footage of reenactment scenes is repeated rather than pictures of the victim. The other two videos re-use the same pictures of victims a lot: in Chroniques criminelles, 24 shots in total show a picture of the victim (alone or with other family members), but only 8 different pictures are used. One particular picture is shown 7 times and another 6 times. They are sometimes simply reused but may as well be used with a slightly different angle or different colors (black and white especially) as shown in Figure 4. Enquêtes criminelles shows 33 pictures of the victim, 11 of which are different. The proportion of re-used pictures is thus exactly the same as in the other program. In this program as well, two pictures become "key" pictures with a higher number of repetitions than the others: one of the pictures is shown 8 times and another one 6 times. The pictures shown belong much more to the "family album" type than to the "photo story" type described by Jermyn (2003: 176): only one of the pictures shown in the three programs is a picture of the victim's wedding and therefore evokes a major event in her life. All the other pictures are 'timeless' insofar as they could have been shot any time before the victim was murdered. The focus therefore is rather on victims' social bonds and not on their life history. This matches what was found in the semantic analysis for nouns, in which relationships form a major thematic field. 

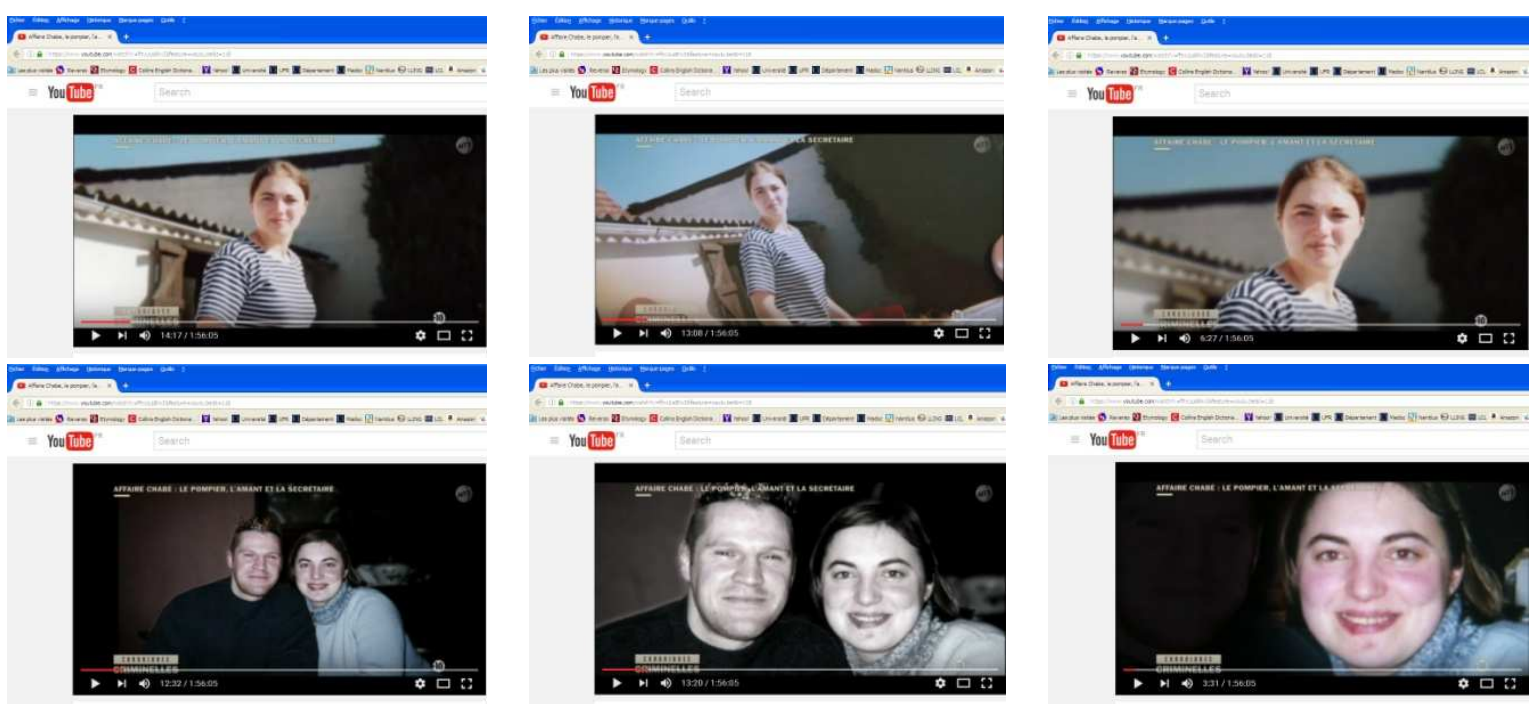

Figure 4. Re-use of pictures with different angles, colors or zoom types in infotainment (all of these pictures are shown in different shots)

\section{Conclusion}

This paper presented a study of crime infotainment, a hybrid type of television program that "transgresses the conventional borderline between fact and fiction" (Jewkes, 2004: 152). Crime infotainment has been found in the literature to be more fear-inducing than other media presenting violent content, as it wrongly induces the perception that crime has increased and that random, violent homicides are the most common criminal acts. Crime infotainment appears "to elevate punitive attitudes" (Callanan, 2005: 177) and encourages support for more conservative political measures. Analyzing three videos of French infotainment programs, the paper proposed a deeper look into the verbal semantic and image content featured in this type of media in order to better understand why crime infotainment provokes such anxiety in the audience.

Semantically speaking, crime and violence are not at all in focus in crime infotainment which has two characteristic features: the first characteristic is that the programs show permanent concern for precision and 'objectivity' in the thematic fields developed in the narratives, with a particular focus on time, space and quantity. These semantic fields are even more present in infotainment than in the print media, and the language register used in infotainment is even more formal than in newspaper articles. This need for more realism and objectivity in the verbal depiction of crime in infotainment is however not mirrored in the images they show. In this respect, infotainment programs are much closer to crime dramas since reenactment scenes in which violent murder is more evoked than actually shown make up the body of the program. This viewpoint stands in stark contrast with the ever-growing appetite for more realistic television, at least in terms of technology (we are now speaking for instance of HDR - High Density Resolution - with which a higher number of pixels provides an image closer to 'reality'). What is common to the semantic thematic fields and the image content of the programs is not violence, or dense information content, but a focus on people and their relationships. We have seen for instance that many shots are re-used throughout a single program and that some of these shots do not even present a clear picture of the people involved in the story. Touching in many respects on other television and movie genres evocative of news 
broadcasts (split screens), but also of horror movies (fade-outs to red) and ghosts stories (fade-outs to white), what crime infotainment tells us about really is not so much frequent yet individual murder cases, but rather who we are as a community and how social order can be disrupted and restored.

The study also showed major differences between the programs shown in France and the same type of program shown in the United-States. In her Master Thesis, Dudkowski (2016) confirmed what was previously noted in the literature, namely that crime documentaries in the US make a large use of shots showing disturbing archive images of crime scenes (images showing blood, murder weapons, corpses, injured body parts, unearthed remains...). This was not found at all in the programs studied here and the reason for this is that the media do not have access to such image content. As shown by Jacobs \& Larrauri (2012), criminal records are not 'public matters' in most European countries contrary to what we find in the US. In France, cameras or any other recording devices are not allowed in tribunals and criminal records are kept in judiciary archives which may only be searched by professionals (magistrates and police). Public access is only granted on court permission after a period of 50 to 70 years after a homicide. The only exceptions are trials that have a historical dimension (accusations of genocides, for instance). Any broadcasting of image content directly linked to a crime is penalized which considerably reduces the opportunities of including 'real' crime scene images in a program. Infotainment producers could include shocking images in the reenactment scenes but as we have seen in this paper, they rely more on suggestion than on the actual showing of disturbing images. This distinguishes this type of program from the horror genre and gives the stories a mythical dimension.

Another difference between the programs in France and the US is that American programs put a strong emphasis on serial killers and the accumulation of random, unmotivated crime ('stranger danger' theory: Stanko, 2000), a feature not found in the French programs (apart from when American stories are imported, which is sometimes the case). What the French programs show is rather crime committed by a family member or a close relationship in very small towns. This is just another way of conveying the feeling that crime may occur anywhere to anyone. The effect is to increase fear of crime in spite of contradictorily low statistics for homicides in the country and to induce more cultural conservative standpoints (Lenz, 2005) as a reaction to crime in the audience who then supports more control and harsher punishment for social deviants.

\section{Acknowledgments}

This research received no specific grant from any funding agency in the public, commercial or notfor-profit sectors. The research presented in this paper is nevertheless part of a larger project on a comparison between infotainment in France and in the US, and I would like to thank two undergraduate students for their participation in the project as part of their course assessment: Gaëlle Hémion collected the press articles and helped with the analysis of their semantic content into thematic fields and Juliette Le Viavant helped with the annotation of one of the three infotainment videos. 


\section{References}

ANTHONY, L. 2014. AntConc (version 3.4.3) [Computer program]. Available: http://www.laurenceanthony.net/.

BEDNAREK, M. 2016. Investigating evaluation and news values in news items that are shared through social media. Corpora, 11(2), 227-257.

BOERSMA, P. \& WEENINK, D. 2009. Praat: doing phonetics by computer (Version 5.1.05) [Computer program]. Available: http://www.fon.hum.uva.nl/praat/.

CALLANAN, V. J. 2005. Feeding the Fear of Crime. Crime-related Media and Support for Three Strikes, New York, LFB Scholarly Publishing LLC.

CAVENDER, G. \& BOND-MAUPIN, L. 1993. Fear and Loathing on Reality Television: An Analysis of "America's Most Wanted" and "Unsolved Mysteries". Sociological Inquiry, 63(3), 305-317.

CAVENDER, G. \& DEUTSCH, S. K. 2007. CSI and moral authority: The police and science. Crime, Media, Culture, 3(1), 67-81.

CHABOT, J., KASPARIAN, S. \& DESJARDINS, P. 2008. Les mots pour le dire. Analyse d'un corpus de presse canadienne française sur le génocide arménien (1915-1920). In: HEIDEN, S. \& PINCEMIN, B. (eds.) Ges Journées internationales d'Analyse statistique des Données Textuelles. Lyon: Presses universitaires de Lyon.

CHERMAK, S. \& CHAPMAN, N. M. 2007. Predicting crime story salience: A replication. Journal of Criminal Justice, 35, 351-363.

COTTER, R., DE LINT, W. \& O'CONNOR, D. 2008. Ordered Images: Cooking Reality in Cops. Journal of Criminal Justice and Popular Culture, 15(3), 277-290.

DUDKOWSKI, E. 2016. On the Case: Linguistic and Visual Design of Crime Documentaries. Master Thesis. University of Nantes.

GRABER, D. A. 1994. The Infotainment Quotient in Routine Television News: A Director's Perspective. Discourse \& Society, 5(4), 483-508.

GREER, C. 2007. News Media, Victims and Crime. In: DAVIES, P., FRANCIS, P. \& GREE, C. (eds.) Victims, Crime and Society. Los Angeles, London: Sage Publications.

GREER, C., FERRELL, J. \& JEWKES, Y. 2007. It's the image that matters: Style, substance and critical scholarship. Crime, Media, Culture, 3(1), 5-10.

HAIG, E. 2008. A Critical Discourse Analysis of Discourse Strategies in Reports of Youth Crime in UK Radio News. メディアと文化, 4, 33-55.

INNES, M. 2003. 'Signal crimes': detective work, mass media and constructing collective memory. In: MASON, P. (ed.) Criminal Visions. Media representations of crime and justice. London: Willan Publishing.

JACOBS, J. B. \& LARRAURI, E. 2012. Are criminal convictions a public matter? The USA and Spain. Punishment \& Society, 14(1), 3-28.

JERMYN, D. 2003. Photo stories and family albums: imaging criminals and victims on Crimewatch UK. In: MASON, P. (ed.) Criminal Visions. Media representations of crime and justice. London: Willan Publishing.

JEWKES, Y. 2004. Media and Crime, London, Thousand Oaks, New Delhi, Sage Publications.

KATZ, J. 1987. What makes crime 'news'? Media, Culture and Society, 9, 47-75.

$\mathrm{KOHM}$, S. A. 2009. Naming, shaming and criminal justice: Mass-mediated humiliation as entertainment and punishment. Crime, Media, Culture, 5, 188-205.

KORT-BUTLER, L. A. \& SITTNER HARTSHORN, K. J. 2011. Watching the Detectives: Crime Programming, Fear of Crime, and Attitudes About the Criminal Justice System. The Sociological Quarterly, 52, 36-55.

LAM, A. 2014. Making Crime Television. Producing Entertaining Representations of Crime for Television Broadcast, New York, Routledge.

LENZ, T. O. 2005. Conservatism in American Crime Films. Journal of Criminal Justice and Popular Culture, 12(2), 116-134. 
NABI, R. L., BIELY, E. N., MORGAN, J. \& STITT, C. R. 2003. Reality-Based Television Programming and the Psychology of Its Appeal. Media Psychology, 5, 303-330.

PEELO, M. 2006. Framing homicide narratives in newspapers: Mediated witness and the construction of virtual victimhood. Crime, Media, Culture, 2(2), 159-175.

REINER, R. 2002. Media Made Criminality: The Representation of Crime in the Mass Media. In: REINER, R., MAGUIRE, M. \& MORGAN, R. (eds.) The Oxford Handbook of Criminology. Oxford: Oxford University Press.

SLOETJES, H. \& WITTENBURG, P. 2008. Annotation by category - ELAN and ISO DCR. 6th International Conference on Language Resources and Evaluation (LREC 2008). Marrakech, Morocco.

SMOLEJ, M. 2011. Violence in Crime-Appeal Programming and in Crime Statistics. A Content Analysis of Finnish Poliisi-TV. Nordicom Review, 32, 59-73.

STANKO, E. (2000). Naturalising danger: Women, fear and personal safety. In: Dangerous Offenders: Punishment \& Social Order, M. BROWN and J. PRATT (Eds.), 147-163. London: Routledge.

SURETTE, R. 2011. Media, Crime, and Criminal Justice Images, Realities, and Policies, Belmont, CA, Wadsworth.

TABBERT, U. 2015. Crime and Corpus. The linguistic representation of crime in the press, Amsterdam / Philadelphia, John Benjamins Publishing Company.

VAN DIJK, T. A. 1995a. Discourse analysis as ideology analysis. In: SCHÄFFNER, C. \& WENDEN, A. (eds.) Language and Peace. Aldershot: Dartmouth Publishing.

VAN DIJK, T. A. 1995b. Ideological Discourse Analysis. New Courant, 4, 135-161.

VAN DIJK, T. A. 2006. Ideology and discourse analysis. Journal of Political Ideologies, 11(2), 115-140.

\footnotetext{
'A distinction is generally made between economic conservative views (freemarket, private healthcare, etc.) and cultural conservative views on topics like abortion, same-sex marriage, death penalty, etc.

ii The narrative design of both videos and press articles will be analyzed fully in another paper in preparation.

iii Institut National de la Statistique et des Etudes Economiques (National Institute for Statistics and Economic Sciences), http://www.insee.fr/fr/

iv Observatoire National de la Délinquance et des Réponses Pénales (National Observatory for Crime and Delinquency), ondrp@inhesj.fr

"Could and should are full verbs in French ("falloir" and "devoir"). Instances of have and be were not taken into account as it would have been too difficult to distinguish verbs from auxiliaries in AntConc, especially in French which has a full conjugation paradigm for number and tense.
} 